\title{
Angiographic Comparison of Coronary Artery Disease between Diabetic Men and Women
}

\author{
MS Mamun, AAS Majumder, M Ullah, S Alam \\ Department of Cardiology, National Institute of Cardiovascular Disease, Dhaka.
}

\begin{abstract}
Key words:

Coronary artery

disease,

Coronary

angiography,

Diabetes

mellitus,

women.

Background: Cardiovascular diseases are the leading cause of death and morbidity in diabetic patients and this group is two to four times as likely to develop cardiovascular disease than the nondiabetic group, women being specially involved in this situation. In women, diabetes appear to be a stronger risk factor for the development of coronary heart disease than in men regardless of age, menopausal status and whether or not the patient is insulin or non-insulin dependent. Objective of this study was to compare the angiographic extent of coronary artery disease between diabetic men and diabetic women.

Method: This observational study was undertaken on 100 diabetic patients ( 50 women and 50 men) admitted inNational Institute of Cardiovascular disease (NICVD) during the period of July, 2006 to April ,2007.Diabetic women with coronary artery disease constitute the study group-I and diabetic men with coronary artery disease matched for age ( \pm 5 years) and risk factors, the study group-II . Coronary angiography was done in all patients \& findings were analyzed. Segmental distribution method for coronary artery lesions was used to describe the distribution of atherosclerotis in coronary artery.

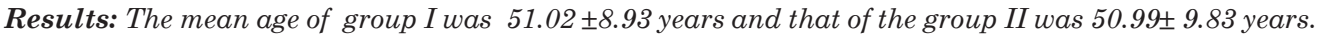
In this study it was found that Diabetic women with coronary artery disease (CAD) had a higher coronary artery score, CAS (11.02 \pm 5.034$)$ as compared to the diabetic men with $C A D(8.04 \pm 4.866)(p<0.001)$. Diabetic women had also higher number of diseased vessels ( $78.67 \%$ vs $67.34 \%$; $p<0.01$ ) and higher number of vessel score 3 ( $58 \%$ vs 34\%; $<<0.001)$. As compared to the diabetic men, diabetic women had a higher total number of coronary artery lesions (183 vs 136; $p<0.001$ ), a higher number of lesions per patient (3.66/ patients vs 2.72 / patients; $p<0.001)$ and a higher number of diffuse vessels $(13.56 \%$ vs $8.91 \% ; p<0.05)$.

Conclusion: Diabetic women with coronary artery disease have more severe disease on coronary angiography as compared to diabetic men with coronary artery disease. The diffuse coronary artery involvement was also significantly higher in diabetic women than men.
\end{abstract}

(Cardiovasc. j. 2013; 6(1): 3-9)

\section{Introduction:}

Cardiovascular diseases are the leading cause of death and morbidity in diabetic patients and this group is two to four times as likely to develop cardiovascular disease than the nondiabetic group, women being specially involved in this situation. ${ }^{1}$ Diabetes is a stronger risk factor for coronary artery disease in women than in men, with a 3- to 7 fold higher coronary artery disease incidence and mortality compared to a 2- to 3 - fold higher risk in men. ${ }^{2}$ In women with acute coronary syndrome diabetes is associated with higher risk of presenting with ST-elevation acute coronary syndrome, developing Q-wave MI, and of in-hospital mortality, whereas in men with acute coronary syndrome diabetes is not significantly associated with increased risk of either. These findings suggest a differential effect of diabetes on the pathophysiology of acute coronary syndrome based on the patient's sex. ${ }^{3}$ In patients undergoing angiography, diabetes, especially in women, is associated with more severe and diffuse coronary atherosclerosis which is not explained by either the traditional risk factors or the presence of proteinuria. On follow-up, these patients experience an excess of cardiac deaths, to which coronary atherosclerosis and proteinuria make independent, quantitative contributions. $^{4-6}$ Diabetic women have a three to seven fold increased risk of death from coronary heart disease compared with non-diabetic

Address Correspondance: Dr. Md. Sk. Mamun, Junior Consultant (Cardiology). Hathazari Health Complex, Chittagong, Bangladesh, E-mail: mamun_card@yahoo.com 
women. ${ }^{7}$ Outcomes after PTCA or CABG are less favorable in diabetic women compared with those without diabetes. ${ }^{8}$

Nevertheless, coronary angiography has not been consistently evaluated in diabetic women. Studies demonstrating detailed angiographic pattern of coronary artery disease in diabetic women are lacking in our country. So in this prospective study the extent and severity of coronary artery disease in our diabetic women was analyzed.

Study Methods: This observational study was undertaken on 100 diabetic patients ( 50 women and 50 men). Diabetic women with coronary artery disease constituted the study group-I and diabetic men with coronary artery disease matched for age ( \pm 5 years) and risk factors, the study group-II. Patients with any of the followings were excluded from the study: previous history of PTCA or CABG, co- morbid conditions such as severe renal impairment, valvular heart diseases, and congenital heart disease. Written informed consent was obtained from all the subjects.
Coronary angiography was done in all patients \& findings were analyzed by eye estimation in standard views. Segmental distribution method for coronary artery lesions described by Dortimer et al. ${ }^{9}$ was used to describe the distribution of atherosclerotic lesions in the left main (LM), left anterior descending, left circumflex and right coronary artery and a scoring system to determine the severity of coronary artery disease was used. Severity of lesions was graded as - 0 -no disease; 1 -intimal disease to less than $50 \%$ stenosis; $2-50$ to $69 \%$ stenosis;3-70 to $95 \%$ stenosis; $4-96$ to $99 \%$ or subtotal stenosis; and 5-totally occluded. The maximum score for any vessel was the sum of the score of all disease segments.

$\mathrm{CAD}$ was considered to involve a vessel diffusely - if three of five segments of the LAD had significant stenosis ( $\geq 70 \%$, grades $3-5)$; if three of five segments of dominant LCX graded 3 to 5 ; if two of four segment of the non dominant LCX graded 3 to 5 ; or if two of four segment of the dominant RCA graded 3 to 5 .
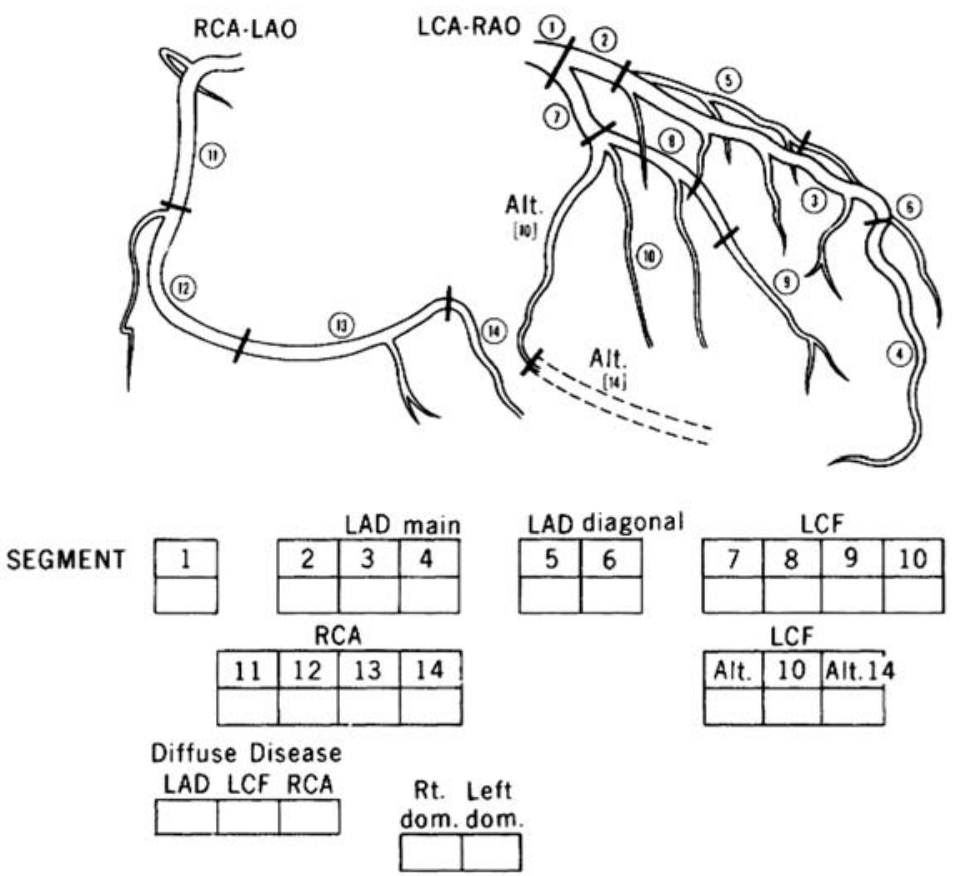

Fig.-1: The segments into which the coronary tree was divided for the evaluation of the extent and severity of stenosis. 
Vessel score ranged from 0 to 3, depending on the number of vessels involved with a significant stenosis $\left(70 \%\right.$ or greater). ${ }^{10}$

\section{Statistical analysis}

The collected data were checked and coded manually and entered into a computer. The numerical data obtained from the study were analyzed and significance of difference was estimated by using the statistical method.

Data were expressed in frequency, percentage; mean \pm standard deviation as applicable. Chisquare test, students t test and Fishers exact test or others were used for comparison between groups as applicable. All data were analyzed by using computer based SPSS (statistical programme for social science) programme (version 11). p value $<0.05$ was considered significant.

\section{Results:}

Mean age of group I patients was $51.02 \pm 8.93$ years and that of group II patients was 50.99 9.83 years. Analysis revealed no statistically significant mean age difference between two groups ( $\mathrm{p}>0.05)$.

Hypertension was highest among the risk factors for coronary artery disease (60\%) followed by dyslipidaemia (40\%), family history(30\%), smoking(16\%) and others(8\%) in group I. Among group II smoking history was highest(66\%) followed by hypertension(56\%), dyslipidaemia (34\%), family history(24\%) and others(14\%).No statistically significant difference of risk factors for CAD was found between two groups of patients $(p>0.05)$ except smoking $(p=0.023)$. In group I highest percentage (56.0\%) had myocardial infarction followed by unstable angina $(22.0 \%)$, stable angina (14.0\%) and NSTEMI

Table-I

Demographic and baseline clinical parameters of the study population $(n=100)$

\begin{tabular}{|c|c|c|c|c|c|}
\hline \multirow{4}{*}{$\begin{array}{l}\text { Parameters } \\
\text { Age in years }(\text { mean } \pm \mathrm{SD}) \\
\text { Range (yrs) }\end{array}$} & \multirow{3}{*}{\multicolumn{2}{|c|}{$\begin{array}{c}\text { Group I }(\mathrm{n}=50) \\
51.02 \pm 8.93 \\
39-65 \\
\end{array}$}} & \multirow{3}{*}{\multicolumn{2}{|c|}{$\begin{array}{c}\text { Group } I I(\mathrm{n}=50) \\
50.99 \pm 9.83 \\
35-67 \\
\end{array}$}} & \multirow{4}{*}{$\begin{array}{l}\text { P-value } \\
{ }^{\mathrm{a}} 0.860^{\mathrm{NS}}\end{array}$} \\
\hline & & & & & \\
\hline & & & & & \\
\hline & $\overline{\text { no }}$ & $\%$ & $\overline{\text { no }}$ & $\overline{\%}$ & \\
\hline \multicolumn{6}{|l|}{ Risk factors } \\
\hline Smoker & 8 & 16.0 & 33 & 66.0 & ${ }^{b} 0.023^{\mathrm{s}}$ \\
\hline Hypertension & 30 & 60.0 & 28 & 56.0 & ${ }^{\mathrm{b}} 0.688^{\mathrm{NS}}$ \\
\hline Dyslipidemia & 20 & 40.0 & 17 & 34.0 & ${ }^{\mathrm{b}} 0.317^{\mathrm{NS}}$ \\
\hline Family history & 15 & 30.0 & 12 & 24.0 & ${ }^{\mathrm{b}} 0.218^{\mathrm{NS}}$ \\
\hline Others & 4 & 8.0 & 7 & 14.0 & ${ }^{\mathrm{b}} 0.208^{\mathrm{NS}}$ \\
\hline \multicolumn{6}{|l|}{ Clinical Diagnosis } \\
\hline Stable angina & 7 & 14.0 & 7 & 14.0 & ${ }^{\mathrm{b}} 1.00^{\mathrm{NS}}$ \\
\hline Unstable angina & 11 & 22.0 & 11 & 22.0 & ${ }^{\mathrm{b}} 0.656^{\mathrm{NS}}$ \\
\hline NSTEMI & 4 & 8.0 & 4 & 8.0 & ${ }^{\mathrm{b}} 0.617^{\mathrm{NS}}$ \\
\hline Myocardial infarction & 28 & 56.0 & 28 & 56.0 & \\
\hline Anterior & 7 & 14.0 & 7 & 14.0 & ${ }^{\mathrm{b}} 0.458^{\mathrm{NS}}$ \\
\hline Ext. anterior & 4 & 8.0 & 4 & 8.0 & ${ }^{\mathrm{b}} 0.556^{\mathrm{NS}}$ \\
\hline Anteroseptal & 6 & 12.0 & 5 & 10.0 & $\mathrm{~b} 0.356^{\mathrm{NS}}$ \\
\hline Inferior & 10 & 20.0 & 12 & 24.0 & ${ }^{\mathrm{b}} 0.546^{\mathrm{NS}}$ \\
\hline High lateral & 1 & 2.0 & 0 & 0.0 & ${ }^{\mathrm{b}} 0.602^{\mathrm{NS}}$ \\
\hline
\end{tabular}

Group I : Diabetic women ,Group II: Diabetic men ${ }^{\mathrm{a}} \mathrm{p}$ value reached from unpaired student's t test, ${ }^{\mathrm{b}} \mathrm{p}$ value reached from chisquare test, $\mathrm{NS}=$ Not significant, $\mathrm{S}=$ Significant 
Table-II

Distribution of study patients by diabetic status

\begin{tabular}{|c|c|c|c|c|c|}
\hline \multirow{5}{*}{$\begin{array}{c}\text { Parameter } \\
\text { Duration } \\
\text { Mean } \\
\text { Range }\end{array}$} & \multicolumn{2}{|c|}{ Group I $(\mathrm{n}=50)$} & \multicolumn{2}{|c|}{ Group II $(\mathrm{n}=50)$} & \multirow[t]{2}{*}{ P-value } \\
\hline & \multirow{3}{*}{\multicolumn{2}{|c|}{$\begin{array}{c}7.1 \pm 3.1 \\
2-13\end{array}$}} & \multirow{3}{*}{\multicolumn{2}{|c|}{$\begin{array}{c}7.68 \pm 4.9 \\
2-18\end{array}$}} & \\
\hline & & & & & \multirow[t]{3}{*}{${ }^{\mathrm{a}} 0.192^{\mathrm{N}}$} \\
\hline & & & & & \\
\hline & no & $\%$ & no & $\%$ & \\
\hline Known & 42 & 84.0 & 40 & 80.0 & ${ }^{\mathrm{b}} 0.992^{\mathrm{NS}}$ \\
\hline Diagnosed at CAG & 8 & 16.0 & 10 & 20.0 & $\mathrm{~b}^{\mathrm{b}} 0.245^{\mathrm{NS}}$ \\
\hline Controlled & 18 & 36.0 & 22 & 44.0 & $\mathrm{~b}_{0.158^{\mathrm{NS}}}$ \\
\hline Uncontrolled & 24 & 48.0 & 20 & 40.0 & ${ }^{\mathrm{b}} 0.099^{\mathrm{NS}}$ \\
\hline \multicolumn{6}{|l|}{ Therapy } \\
\hline Diet & 2 & 4.0 & 4 & 8.0 & $\mathrm{~b}^{\mathrm{b}} 0.079^{\mathrm{NS}}$ \\
\hline OHA & 33 & 66.0 & 30 & 60.0 & ${ }^{\mathrm{b}} 0.123^{\mathrm{NS}}$ \\
\hline Insulin & 2 & 4.0 & 4 & 8.0 & ${ }^{\mathrm{b}} 0.079^{\mathrm{NS}}$ \\
\hline Insulin+OHA & 5 & 10.0 & 3 & 6.0 & $\mathrm{~b} 0.504^{\mathrm{NS}}$ \\
\hline
\end{tabular}

Group I : Diabetic women, Group II: Diabetic men, ${ }^{a} \mathrm{p}$ value reached from unpaired student's t test, ${ }^{\mathrm{b}} \mathrm{p}$ value reached from chisquare test and Fisher's exact test.NS= Not significant

(8.0\%). Similar pattern of diagnosis was noted in group II patients with highest percentage (56.0\%) Myocardial Infarction followed by unstable angina (22.0\%) and stable angina (14.0\%) and NSTEMI(8.0\%).Analysis revealed no statistically significant difference between two groups of patients $(p>0.05)$.

Mean duration of diabetes was $7.1 \pm 3.1$ years (range 2-13 years) in group I and $7.68 \pm 4.9$ years (range 2-18 years) in group II. 36\% were controlled and $48 \%$ were uncontrolled in group I, in comparison $44 \%$ were controlled and $40 \%$ were uncontrolled in group II. The difference between two group was not statistically significant $(p>0.05)$.

The mean percent of ejection fraction was 55.4 43.9 in group I patients and $56.1 \pm 4.1$ in group II patients which was not statistically significant $(p>0.05)$.
Group I had significant number of triple vessel disease than the group II [29(58.0\%) vs 19(38.0\%); $\mathrm{p}<0.001]$. Group II had increased number of single and double vessel disease than group I but the difference were not statistically significant $(p>0.05)$.

Mean coronary artery score (CAS)in group I and group II were $11.02 \pm 5.034$ and $8.04 \pm 4.866$ respectively and the difference was statistically significant $(p<0.001)$, more coronary artery segment involved in group I than the group II $(3.66 \pm 1.793$ vs $2.72 \pm 1.671)$ and the difference was statistically significant $(\mathrm{p}<0.001)$, the diseased vessel was $118(78.67 \%)$ in group I and 101(67.34\%) in group II. Analysis found statistically significant difference between two groups $(\mathrm{p}=0.001)$.

Table-III

Distribution of study patients by mean percentage of ejection fraction $(n=100)$

\begin{tabular}{|c|c|c|c|c|c|}
\hline \multirow[t]{2}{*}{$\begin{array}{l}\text { Ejection } \\
\text { Fraction (\%) }\end{array}$} & \multicolumn{2}{|c|}{$\begin{array}{c}\text { Group I } \\
(\mathrm{n}=50)\end{array}$} & \multicolumn{2}{|c|}{$\begin{array}{c}\text { Group II } \\
(\mathrm{n}=50)\end{array}$} & \multirow[t]{2}{*}{$\mathrm{p}$ value } \\
\hline & $\mathrm{n}$ & $\%$ & $\mathrm{n}$ & $\%$ & \\
\hline$<50$ & 9 & 18.0 & 5 & 10.0 & ${ }^{\mathrm{a}} 0.500^{\mathrm{NS}}$ \\
\hline$\geq 50$ & 41 & 82.0 & 45 & 90.0 & \\
\hline MeanSD & 55.4 & 3.9 & 56.1 & 4.1 & ${ }^{\mathrm{b}} 0.632^{\mathrm{NS}}$ \\
\hline
\end{tabular}

Group I : Diabetic women, Group II: Diabetic men, ${ }^{a} \mathrm{p}$ value reached from chi-square test, ${ }^{\mathrm{b}} \mathrm{p}$ value reached from unpaired student's t test, $\mathrm{NS}=$ Not significant 
Table-IV

Distribution of the study population by number of vessel involved $(n=100)$

\begin{tabular}{|c|c|c|c|c|c|}
\hline \multirow{2}{*}{ No. of vessel involved } & \multicolumn{2}{|c|}{ Group I $(\mathrm{n}=50)$} & \multicolumn{2}{|c|}{ Group II $(\mathrm{n}=50)$} & \multirow[t]{2}{*}{ P-value } \\
\hline & No & $\%$ & No & $\%$ & \\
\hline Normal coronaries & 2 & 4.0 & 3 & 6.0 & $0.108^{\mathrm{NS}}$ \\
\hline SVD & 7 & 14.0 & 12 & 24.0 & $0.247^{\mathrm{NS}}$ \\
\hline DVD & 12 & 24.0 & 16 & 32.0 & $0.085^{\mathrm{NS}}$ \\
\hline TVD & 29 & 58.0 & 19 & 38.0 & $<0.001^{\mathrm{S}}$ \\
\hline
\end{tabular}

Group I : Diabetic women, Group II: Diabetic men, p value reached from chi-square test and Fisher's exact test, NS= Not significant, $\mathrm{S}=$ significant

Table-V

Extent of coronary artery disease in the study population

\begin{tabular}{lccc}
\hline Arteries & Group I $(\mathrm{n}=50)$ & Group II $(\mathrm{n}=50)$ & P-value \\
\hline Coronary score(CAS) & & & \\
$\quad$ Total score & 551 & 402 & \\
$\quad$ Score/patient & $11.02 \pm 5.034$ & $8.04 \pm 4.866$ & ${ }^{\mathrm{a}} 0.000^{* * *}$ \\
Segment involved & & & \\
$\quad$ Total segment & 183 & 136 & ${ }^{\mathrm{a}} 0.000^{* * *}$ \\
$\quad$ Segment /patient & $3.66 \pm 1.793$ & $2.72 \pm 1.671$ & $\mathrm{~b}^{\mathrm{b}} 0.001^{\mathrm{S}}$ \\
Diseased vessels & $118(78.67 \%)$ & $101(67.34 \%)$ &
\end{tabular}

Group I : Diabetic women, Group II: Diabetic men, ${ }^{a} \mathrm{p}$ value reached from unpaired student's t test, ${ }^{\mathrm{b}} \mathrm{p}$ value reached from chisquare test, $\mathrm{S}=$ significant, ${ }^{* * *}$ p value is significant at the level of $<0.001$

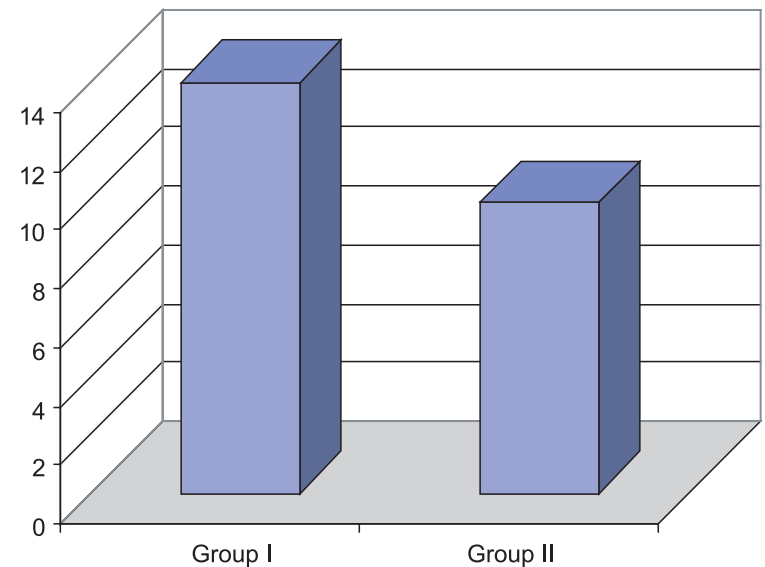

Fig.-2: Percentage of coronary vessels diffusely diseased in study

$13.56 \%$ of group I had diffuse disease whereas in group II it was $8.91 \%$. Analysis found statistically significant difference between group. I and group II $(\mathrm{p}=<0.05)$.

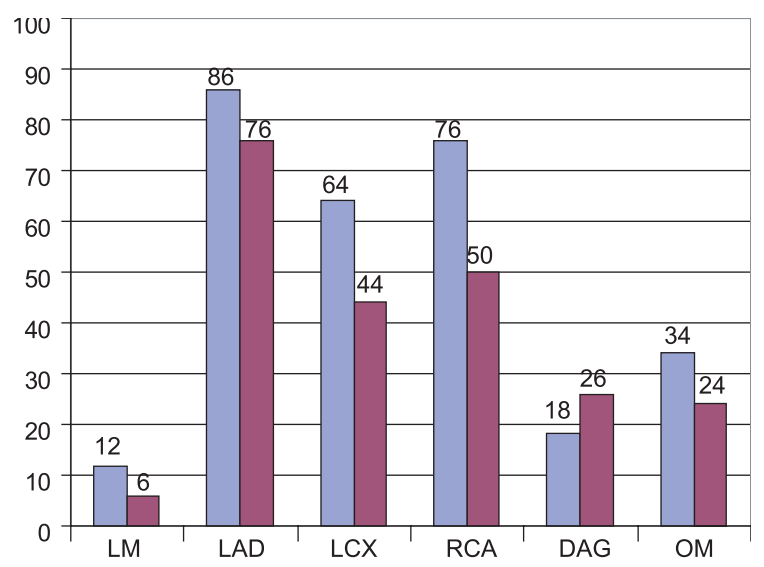

Fig 3: Distribution of study population by involvement of individual coronary artery $(n=100)$

Group I had more involvement of LCX [32(64.0\%) vs22(44.0\%)] and RCA [38(76.0\%) vs $25(50.0 \%)]$ and the difference was statistically significant $(p=<0.05)$. 


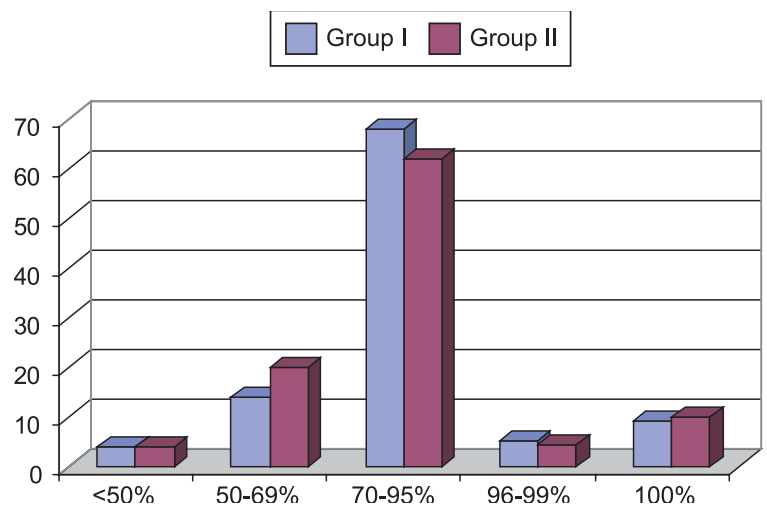

Fig.-4: Distribution of lesions according to severity of stenosis in study population $(n=100)$

Most of the lesions were significantly obstructive $(>70 \%)$ in both the groups. Lesions involving $70-95 \%$ of luminal area were $68.85 \%$ in group I and $61.76 \%$ in group II and the difference is statistically significant $(\mathrm{p}<0.05)$.

\section{Discussion:}

This study was a prospective observational study conducted in the National Institute of Cardiovascular Diseases (NICVD), Dhaka. The aim of the study was to compare the angiographic extent of coronary artery disease between diabetic men and women. We analyzed our population of diabetic patients coming for coronary angiography to determine if diabetic women have more severe and diffuse disease of their vessels on coronary angiography compared to diabetic men.

In the present study mean age of diabetic women and diabetic men were $51.02 \pm 8.93$ years and $50.99 \pm 9.83$ years respectively. Among the risk factors, smoking was significantly higher in diabetic men than diabetic women. No significant difference was seen in hypertension $(60 \%$ vs $56 \%$ ), dyslipidemia ( $40 \%$ vs $36 \%$ ), family history (30\% vs $24 \%$ ) and others ( $8 \%$ vs $14 \%$ ) in diabetic women and diabetic men. Rachel Huxley et al. ${ }^{11}$ also found similar distribution of risk factors in diabetic women and men. Our observations are also in accordance with that of Rahman. ${ }^{12,13}$ where he found smoking (66\%), hypertension (58\%), dyslipidemia(58\%) and positive family history (30\%) were the major risk factors in descending order. Large number of our patients presented with myocardial infarction in both diabetic women and diabetic men followed by unstable angina, stable angina and NSTEMI. As clinical diagnosis carefully matched between diabetic women and men, there was no difference between two groups. Among the patients of myocardial infarction, inferior myocardial infarction is more common than anterior myocardial infarction both in diabetic women and men. Nasiruddin more patients having anterior myocardial infarction than inferior. ${ }^{14}$

We found that diabetic women had more severe disease on coronary angiography in comparison to diabetic men as reflected by a higher coronary artery stenosis score, a higher incidence of diseased vessel, more triple vessel disease and more disease segment per patients. Natali et al. ${ }^{4}$ had reported a higher atherosclerosis score a in diabetic women than men which supported our study result. Our result was also in accordance with the findings by Rachel Huxley et al. ${ }^{11}$ where in a meta-analysis of 37 prospective cohort studies on excess risk of fatal coronary heart disease associated with diabetes in men and women showed that the relative risk of fatal coronary heart disease in diabetic women was significantly greater than diabetic men: $3.50(95 \%$ confidence interval 2.70 to 4.53 ) vs 2.06 , (1.81 to 2.34). Another meta-analysis of 16 prospective studies by Warren L. Lee et al. ${ }^{15}$ also showed similar result. This study showed the relative risk of coronary death in diabetic women was higher than diabetic men: 2.58 (95\% confidence interval 2.05 to 3.26 ) vs 1.85 (1.47 to 2.33 ). This difference is statistically significant $(\mathrm{p}=0.045)$.

We used stringent criteria to define diffuseness of CAD using the segmental distribution method for coronary artery lesion. The diffuse coronary artery disease in diabetic women was found to be significantly more than in diabetic men. Diffuse involvement is more common in RCA followed by LCX and LAD.

Regarding the incidence and location of obstructive lesions according to severity, significant obstructive lesion $(\geq 70 \%)$ is significantly higher in diabetic women than diabetic men whereas lesions involving $<70 \%$ of luminal area were more common in diabetic men. Our result were in accordance with Rachel Huxley et al. ${ }^{11}$ where $80 \%$ and $73 \%$ of the lesions were $\geq 70 \%$ stenosed in diabetic women and men 
respectively. Nasiruddin ${ }^{14}$ also found $66 \%$ lesions were $>70 \%$ stenosed.

Multivariate analysis showed that diabetes is a strong and independent predictor of coronary heart disease in both group even after adjustment for potential confounders (i.e., age, hypertension, dyslipidemia, history of smoking, family history and other risk factors) ( OR 3.50; 95\% CI 2.70-4.53 in group I and OR 2.05; 95\% CI 1.25-3.40 in group II).

\section{Conclusion:}

Diabetic women with coronary artery disease have more severe disease as compared to diabetic men with coronary artery disease. Diffuseness in the coronary artery involvement is also significantly higher in diabetic women than men.

CAD is the leading cause of death in women. The failure to treat women as vigorously as men will contribute to the worst outcome. More aggressive treatment and better control of other coronary heart disease risk factor levels in women with diabetes is likely to substantially reduce the excess coronary heart disease mortality in this group. The stronger association between diabetes and coronary heart disease in women demands the early detection of coronary artery disease even in less symptomatic patients by stress test and coronary angiography with an aim to early revascularization by coronary intervention or coronary artery bypass graft.

\section{Conflict of Interest - None.}

\section{References:}

1. Sousa JMA, Herrman JLV, Teodoro M, Diogo S, Terceiro BB, Paolo AAV \& Carvalho ACC. Comparison of coronary angiography findings in diabetic and nondiabetic women with non-ST-segment-elevation acute coronary syndrome. Arq.Bras.Cardiol 2006; 86: 67-76.

2. Barrett-Connor EL, Cohn BA, Wingard DL \& EdelsteinSl. Why is diabetes mellitus a stronger risk factor for fatal ischemic heart disease in women than in men? The Rancho Bernardo Study. JAMA 1991; 265: 627-631.

3. Dotevall A, Hasdai D, Wallentin L, Battler A \& Rosengren A. Diabetes mellitus: clinical presentation and outcome in men and women with acute coronary syndromes. Data from the Euro Heart Survey ACS. Diabetic Medicine 2005; 22 (11):1542-1550.
4. Natali A, Vichi S, Landi P,Severi S, Abbate A \& Ferrannini E. Coronary atherosclerosis in type II dibetes:angiographic findings and clinical outcome. Diabetologia 2000; 43(5): 632-641.

5. Lindvall B, Brorsson B, Herlitz J, Albertsson P \& Werko L. Comparison of diabetic and nondiabetic patients referred for coronary angiography. Int J Cardiol 1999; 70(1): 33-42.

6. Rennert NJ \& Charney P. Preventing cardiovascular disease in diabetes and glucose intolerance: Evidence and implication for care. Primary Care Clin North Am 2003; 30:569-592.

7. Grundy SM, Pasternak R, Greenland P, Smith S \& Fuster V. Assesment of cardiovascular risks by use of multiple risk factor assessment equation: A statement for healthcare professionals from the American Heart Association and the American College of Cardiology. Circulation 1999; 100(13): 1481-1492.

8. Jousilahti P, Vartiainen E, Tuomilehto J \& Puska P. Sex,age, cardiovascular risk factors and coronary heart disease:A prospective follow-up study of 14,786 middle aged men and women in Finland. Circulation 1999; 99(9): 1165-1172.

9. Dortimer AC, Shenoy PN, Shiroff RA, Leaman DM, Babb JD, Liedtke AJ \& Zelis R. Diffuse coronary artery disease in diabetic patients-facts or fiction? Circulation 1978; 1(57): 133-136.

10. Sullivan DR, Marwick TR \& Freedman SB. A new method of scoring coronary angiograms to reflect extent of coronary atherosclerosis and improve correlation with major risk factors. Am Heart J 1990; 119: 1262.

11. Huxly R, Barzi F \& Woodward M. Excess risk of fatal coronary heart disease associated with diabetes in men and women:meta-analysis of 37 prospective cohort studies. BMJ 2006; 332: 73-78.

12. Rahman MA, Ali MA, Majumder AAS, Haque KMHSS, Banoo H \& Zaman MA. Dyslipidemia and coronary arterial disease. Bangladesh Heart J 2001; (16): 30-35.

13. Rahman S, Akanda M A K, Masky A, Malik F \& Ahmed N. Prediction of immediate outcome of intracoronary stent implantation by lesion morphology. Bangladesh Heart $J$ 2001;16: 1-8.

14. Nasiruddin S, Chowdhury AW, Khalequzzaman MD, Baqui MA, Malik F, Ali M, Majumder AAS \& Sdequzzaman M. Diffuse coronary artery disease in type -2 diabetic patients:an angiographic study', Bangladesh Heart Journal 2005; 20(2): 44-48.

15. Lee WL, Cheung AM, Cape D \& Zinman. Impact of diabetes on coronary artery disease in women and men: a metaanalysis of prospective studies. Diabetes Care 2000; 23(7): 962-968. 